\title{
EXPRESSIONISMO NO CINEMA: 0 GESTO COMO ALEGORIA
}

Luciano Nunes do Vale*

\section{Resumo:}

Acreditamos que a atuação do ator no cinema expressionista alemão assumiu caráter alegórico, marcados por gestos estilizados cuja tensão, concentradas nas mãos e no arfar, deram forma aos tipos tiranos e autômatos apontados por Siegfried Kracauer em seu De Caligari a Hitler. Partimos da análise das atuações de Conrad Veidt nos filmes $O$ Gabinete do Dr. Caligari e As Mãos de Orlac; e também da leitura de Walter Benjamin e Kracauer, tomando por base o conceito de alegoria do primeiro e os de fenômeno de superfície e culto da evasão do segundo. Dentro da análise de fenômenos descontínuos até então desprezados pela alta cultura que está presente na obra dos dois filósofos, Benjamin apresenta seu conceito de alegoria dentro de seu estudo sobre o Drama Trágico do Barroco alemão (Unsprung des deutschen Trauerspiel) do século XVII como contraponto ao até então predomínio do símbolo classicista; e dentro dessa linha, acabou se tornando um conceito chave para o entendimento das vanguardas. Nesse sentido, a alegoria do autômato se torna emblemática para o desenvolvimento da pesquisa. Primeiro, por se tratar de um tipo presente no cinema de estética expressionista, sempre em contraposição com os tipos tiranos; segundo, porque na concepção de Benjamin, o autômato é o homem que perdeu a experiência e representa os seres que vagueiam na sociedade industrial, movimentando-se de forma mecânica numa completa ausência de sentido. E dessa forma, ao apresentar a Weltschauuung barroca próxima da expressionista, acreditamos que a alegoria seja o ponto de intersecção entre a atuação teatral expressionista e a assimilação de sua forma pela então emergente indústria cultural. Assim, a alegoria do autômato, dentro do estilizado gestual expressionista seria um fenômeno de superfície que, no cinema, teria um significado de culto da evasão apontado por Kracauer em seu artigo Cinema, 1928 e que, posteriormente, seria desenvolvido em seu livro De Caligari a Hitler, de 1947.

Palavras-chave: Expressionismo, alegoria, gesto, cinema alemão, culto da evasão.

Walter Benjamin e Siegfried Kracauer fazem parte de uma geração de intelectuais que incluem também Georg Lukács e Ernst Bloch - que, no início do século XX, deram forma a um Weltanschauung marcado por uma crítica romântica ao capitalismo, personificando aquilo que o jovem Lukács definiu como "apátrida transcendental". Tratava-se

\footnotetext{
* Mestrando em Filosofia pela Universidade Federal de São Paulo (UNIFESP) - Campus de Guarulhos. Orientadora: Lilian Santiago-Ramos. Bolsista CAPES. Parte da pesquisa de mestrado, com apresentações orais em eventos na USP e Unesp em 2013. O resumo foi publicado no caderno de resumos do VII Encontro de Pósgraduação em Filosofia da Unesp, no final de 2013.
} 
de uma sensação de exilio existencial ante o desabrigo de um mundo que perdeu o teto de sua totalidade e se viu estilhaçado na fragmentação da modernidade, aliados a uma visão cosmopolita que não perdia de vista as transformações do capitalismo em escala mundial. Posteriormente, se desenvolveria uma crítica mais materialista e radical com a ascensão nacional-socialista, e o exilio territorial seria um imperativo de sobrevivência para esses intelectuais de ascendência judaica e com posicionamentos de esquerda, com a consolidação do poder nazista em 1933. Aqui, destacamos alguns pontos de contato entre Benjamin e Kracauer, a saber: a análise de fenômenos considerados, até então, diante dos já empoeirados valores da alta cultura. Essas análises estão em conformidade com uma concepção análoga de história comum aos dois pensadores: ambos a concebem como uma micrologia, isto é, uma investigação do todo no micro, focalizando os detritos da história, marginalizados pela historiografia oficial. Daí a análise dos fenômenos de superfície como signo histórico (para usar um conceito de Kracauer) investigar manifestações triviais como a moda, o brinquedo e a opereta que, desprezadas num primeiro momento, revelam muito mais de uma época do que o juízo que essa época faz de si própria (KRACAUER, 2009, p. 91). E, nessa perspectiva de se atentar a esses fenômenos, distinguem-se a análise do cinema e de outras manifestações da então ascendente cultura de massa, que marcariam uma revolução na recepção artística, saindo da contemplação e indo para a distração.

Dentro desse panorama, Benjamin, em seu livro A Origem do Drama Trágico Alemão, mergulharia nos estudos das tragédias alemãs do século XVII e que jamais foram encenadas. Nele é apresentada uma outra leitura do Drama Trágico do Barroco alemão do século XVII, onde se distingue o drama trágico (Trauerspiel) da tragédia (Tragödie), entrando em conflito com os historiadores de sua época. Mas sua escolha pelo Trauerspiel, tem como fator determinante estabelecer pontos de contato entre o Drama Trágico e a alegoria e, com isso, a intenção de uma atualização da literatura barroca pelo Expressionismo alemão. Benjamin reconhece: "Tenho a impressão de que, nos últimos dois séculos, nenhuma época revela, na sua sensibilidade artística, tantas afinidades com a busca de um estilo na literatura do Barroco com ao de nossos dias" (MANHEIM apud BENJAMIN, 2011, p. 44). Assim, levanta a hipótese das afinidades entre o Barroco do século XVII e o Expressionismo no século XX principalmente os sentimentos de luto e melancolia - e a reabilitação da alegoria, então desprezada pelo predomínio do símbolo classicista. Essas afinidades poderiam ser encontradas tanto no plano externo - a violência belicista que marcara o século XVII e que estava marcando o século XX - quanto em um plano interno - marcada pelo desespero, pela angústia, pelo luto e pela melancolia e que se assimilava na Weltanschauung presente na poesia de Johann Christian Hallman (poeta do século XVII) e na poesia de expressionistas como Gottfried Benn, Else Lasker Schüller e Georg Trakl. Dessa forma, o Expressionismo transporta em sua estética e expressão artística o interesse em tudo que carrega o sofrimento humano e no que havia de feio, doentio e repugnante na vida, em que imagens de podridão, violência e morte são parte inseparável da realidade.

Além dos sentimentos de luto e melancolia, sobressai a reabilitação da alegoria, então desprezada pelo predomínio do símbolo classicista. A alegoria é vista pelo filósofo como "reabilitação da história, da temporalidade e da morte na descrição da linguagem humana" (GAGNEBIN, J.M., 2011, p. 35) em oposição ao "ideal de eternidade que o símbolo encarna" (Idem). Benjamin observou o alegórico como uma profundeza sombria que estaria à espreita da perfeição luminosa representada do símbolo, onde o observador tem diante de si "a facies hippocratica da história" (BENJAMIN, 2011, p. 176) onde essa, "com tudo aquilo que tem 
desde o início tem em si de extemporâneo, de sofrimento e de malogro, ganha expressão na imagem de um rosto - melhor, de uma caveira" (Idem). Benjamin afirma no seu trabalho sobre o Drama Trágico alemão o que entende como cerne da contemplação de tipo alegórico: "a exposição barroca e mundana da história como via crucis do mundo: significativa, ela o é apenas nas estações da sua decadência" (Ibidem, 2011, p. 177). Dentro dessa linha, ocorrem estas afinidades eletivas entre o Barroco e Expressionismo, das quais se coadunam o voluntarismo artístico e a predisposição para o grotesco, o exagero e o maneirismo violento. Observa Benjamin: "De fato, o Barroco, como o Expressionismo, é menos uma época do genuíno fazer artístico do que um obstinado voluntarismo artístico. É o que sempre acontece com as chamadas épocas de decadência". Assim sendo, esse voluntarismo acaba sobrepujando o próprio fazer artístico. E acaba se tornando estado de prontidão estética de períodos históricos distintos no tempo (século XVII e XX), porém marcados por uma atmosfera bélica e conturbada. Deste modo, a proximidade entre a alegoria barroca e o Expressionismo se apresenta, no campo estético e artístico, não só como sentimento de luto e melancolia, mas também ao que de há de latente nas ruínas de seus respectivos tempos-históricos: a Guerra dos Trinta Anos e o declínio da Belle Époque que culminaria com a $1^{\text {a }}$ Guerra Mundial. Em ambos, apresentam-se contradições que não se completam; nessas oposições há um convívio duplo e paralelo, onde no que uma característica predomina o seu oposto estará latente, pronto para vir à superfície. Como herança barroca no Expressionismo, esses opostos adquirem fisionomia e postura transtornada, cujos traços e movimentos de torção constituem uma convulsão integradora e que tem, no arfar e no grito, os gestos desesperados de fuga dos tormentos internos do sujeito fraturado. O "dizer o outro" intrínseco a alegoria (originária de allo, outro e agorein, dizer) expõe seu grito tanto na dialética imanente do Trauerspiel (Luto e Jogo) quanto nas contradições de nossa modernidade, estilhaçadas "entre a nostalgia de certezas desaparecidas" (GAGNEBIN, 2011, p.38).

O conceito benjaminiano de alegoria é chave para entendermos os procedimentos das vanguardas estéticas, como posteriormente seria apresentado por Peter Bürger em seu livro Teoria da Vanguarda. Ao mesmo tempo, a alegoria manifesta essa perda do sentido de totalidade, uma sensação comum nas primeiras décadas do século XX, onde a "morte de Deus" nietzscheana e o "desencantamento do mundo" weberiano impulsionam o vazio dessa ignorância em relação ao sentido que caracteriza aquele tempo, em que o sujeito moderno fragmenta-se e, se encontra, tanto na condição de melancólico ante os escombros da tradição - conforme Benjamin - quanto na do exilado - conforme à definição de Lukács do "apátrida transcendental" -: desamparado de uma visão totalizante do mundo que dava um sentido à vida. E, por fim, o próprio Benjamin faz uso da alegoria enquanto imagem do pensamento, destacando a alegoria do autômato, que é por ele empregada numa pluralidade de significações (como a apresentada na primeira de suas Teses sobre o Conceito de História) e que se desenvolve com seu conceito de experiência e de sua perda na modernidade: o autômato representa a figura alegórica mais depurada dessa perda.

Benjamin faz uso da alegoria do autômato numa multiplicidade de significações. Ora para configurar a máquina e seu domínio sobre o homem; ora para configurar o homem automatizado pela máquina e alijado de sua humanidade pelo progresso técnico; ora para configurar a História, marcada pelo oficialismo da versão dos "vencedores" ou pelo automatismo da ideologia do progresso que impregnava a socialdemocracia e o comunismo stalinista; e, por último e, em um sentido mais amplo, configurando o homem que perdeu sua experiência com a modernidade. 
Por sua vez, a figura do autômato também é marcante na tipologia dos filmes expressionistas que marcaram o cinema da República de Weimar - quase sempre como contraponto aos tipos tiranos - e cuja associação de sua figura alegórica com a estilização expressionista tem sua origem em $O$ Gabinete do Dr. Caligari, dirigido por Robert Wiene em 1919. Nesse sentido, as caracterizações de Werner Krauss (o hipnotizador tirânico Caligari) e Conrad Veidt (o sonâmbulo assassino Cesare) são emblemáticas: verdadeiras alegorias da tirania e da submissão. Vindos do teatro, os atores trazem a forma distorcida da forma expressionista em seus contornos de interpretação. No Expressionismo, não há - como no realismo ou no naturalismo - uma mudança gradual e lógica de sentimentos e ações. Pelo contrário, os atores expressionistas são marcados pelos gestos bruscos e expressivos sem nuances intermediárias, assim como por movimentos singulares que ultrapassam a realidade visível, que atingem uma exteriorização imediata.

Outro trabalho marcante de Conrad Veidt, encarnando novamente um tipo autômato, é sua caracterização do pianista Paul Orlac em As Mãos de Orlac (1924), também de Robert Wiene. Nesse filme, Veidt interpreta um famoso pianista que perde as mãos em um acidente de trem. Um cirurgião transplanta no pianista as mãos de um assassino que acabara de ser executado. Sabendo disso, o pianista passa a sentir uma violenta aversão a seus novos membros, que o impede tanto de tocar piano como de tocar sua esposa. Suas mãos são repletas de significados, "instrumentos da vontade que comanda o fazer, pelo qual o homem manifesta sua humanidade (realizando um talento) ou desumanidade (praticando um crime)" (NAZÁRIO, 1999, pp. 192-193). Trata-se do uso do gesto como uma alegoria da ação do sujeito, ou no caso do autômato, da falta de autonomia da ação ou do próprio gesto. A atuação de Veidt dá ênfase a essa interpretação, dando peso ás suas mãos como se se separassem do corpo e tivessem vontade própria. Utilizando com maestria uma espécie de escrita corpórea, Veidt isola um traço da personagem e a sublinha, distanciando-se de um realismo banal. No caso, a mãos crispadas resultantes de tormentos internos. Essa forma intensa de expressão que rompe com gestos cotidianos seria matriz de trabalhos futuros: podemos citar, no cinema, as mãos do infanticida vivido por Peter Lorre em M (1931) de Fritz Lang ou as mãos tatuadas do pastor Harry Powell (Robert Mitchum) em The Night of the Hunter (1955); e no teatro, as mãos trêmulas que pousavam na cabeça utilizadas por Bete Coelho, ao interpretar Joseph K. na montagem de Um Processo, parte da Trilogia Kafka, dirigida por Gerald Thomas em 1988.

Embora seja herança da literatura romântica alemã, a alegoria do autômato corresponderia a uma alegoria da alienação na sociedade industrial dentro do cinema da República de Weimar e que, na interpretação expressionista dos atores, teria evocaria sua "fisionomia latente" (EISNER, 2002, p. 28).

Nesse sentido, essa configuração se aproxima com a própria visão de Siegfried Kracauer diante da modernidade. Sua recepção de A Teoria do Romance foi emblemática para o desenvolvimento de sua trajetória intelectual. O que mais o impressionou livro de Lukács foi o diagnóstico da época, definido como o tempo da "pecaminosidade completa", onde predomina a ausência de sentido num mundo após a queda, que a sensação de exílio do indivíduo cindido e esvaziado após a separação entre a realidade e a essência define a condição do chamado "apátrida transcendental". Todo o processo histórico que caracteriza a modernidade, é visto por Kracauer como a perda crescente de sentido da vida e a separação das esferas da verdade e da existência; o mundo se desintegrando numa multiplicidade de fenômenos que se cristalizam nas condições sociais e econômicas próprias da racionalidade 
capitalista e da alienação presentes nas relações humanas. O sujeito, lançado na populosa solidão das grandes cidades, dentro de um espaço e tempo vazios, circunstâncias que podem ser sintetizadas na expressão de Lukács "desabrigo transcendental" (transzendentale Obachlosigkeit). Essa sensação de vazio e desabrigo se tornaria emblemática da posição de Kracauer enquanto intelectual. Pode-se afirmar que seu exílio não começou em 1933 (a época da chegada do Nacional-Socialismo ao poder na Alemanha); configurações de exílio e desabrigo estão constantemente presentes em sua obra.

Aqueles que Esperam é um de seus artigos mais representativos dessa visão de mundo. Publicado em 1922 no Frankfurter Zeitung (KRACAUER, 2009, pp. 149-160). O ensaio propõe uma atitude de espera, autoconsciente e ativa dos chamados estratos médios (posteriormente objeto de estudo do artigo A Rebelião dos Estratos Médios e do seu estudo Os Empregados, já no final da década de 20). Kracauer direciona-se contra as primeiras tentativas de restauração de sentido para preencher as lacunas do esvaziamento do mal-estar moderno. Imersas num excesso de relações econômicas, vivem desvinculadas e isoladas, sem vínculos de base firme, andando a deriva. $\mathrm{O}$ medo diante do vazio domina essas pessoas. Para Kracauer, mais do que desenrolar os problemas históricos é preciso salientar a situação anímica dessas pessoas: "No fundo elas sofrem de seu exílio da esfera religiosa" (KRACAUER, 2009, p. 151) Assim sendo, a única atitude que desponta para Kracauer é esperar. Uma espera caracterizada por uma estar aberto incessante. Kracauer se mostra extremamente cauteloso com as tentativas com as tentativas de cura desse vazio característico da modernidade, especialmente ao que tange a essas camadas médias da sociedade alemã. De certa forma, o que impressiona é que essas camadas médias, com a crise econômica que marcaria o final dos anos 20, somado ao ressentimento por parte de seus setores sofrerem um processo de "proletarização" seriam presa fácil ao permitirem que seu vazio fosse preenchido com as promessas nazistas.

Porém, logo ocorreria uma virada materialista na trajetória intelectual de Kracauer, que se dá a partir de suas leituras de Marx. Das grandes questões metafísicas em que os fenômenos seriam indícios de declínio e desintegração do mundo, para uma perspectiva em que os fenômenos são manifestações efêmeras da vida cotidiana, onde a cultura de massa então emergente e desprezada por boa parte dos intelectuais tem papel central ao confrontarse com os ultrapassados valores elevados da alta cultura burguesa. Perspectiva já presente no final dos anos vinte em seus artigos no Frankfurter Zeitung no final dos anos vinte.

Em relação às vanguardas, Kracauer tem uma posição ambivalente. Desde seu ensaio "Sobre o expressionismo. Essência e sentido de um movimento de época" [Über den Expressionismus. Wesen und Sinn einer Zeitbewegung] de 1918(KRACAUER apud MACHADO, C.E.J., 2007, p. 193), Kracauer sempre se colocou de maneira critica frente ás vanguardas históricas e ao expressionismo especificamente. Não tem o entusiasmo que Ernst Bloch manifesta no livro O espírito da utopia, também de 1918; tampouco compartilha do antivanguardismo defendido por Georg Lukács nos anos trinta. Por um lado, se manifesta a favor do Expressionismo, no que tange a sua revolta contra um intelecto imobilizado por uma visão cientificista que ignora o "humano", a sua luta contra a realidade, ao seu pacifismo e a sua busca na configuração de um ornamento capaz de conter o humano (o que o aproxima de Ernst Bloch); por outro lado Kracauer vê o Expressionismo como fenômeno de transição, mais um "grito a ação e à arte do que um grito e uma arte específicos" (Ibidem, 2007, p. 194). Da mesma maneira, Benjamin tinha uma atitude ambígua em relação ao movimento 
propriamente dito; era-lhe próximo mas somente em relação à atitude (BRETAS, A., 2008, p. 156). Como afirma Gershom Scholem: “A imoderação surrealista atraía-o mais profundamente do que a pretensão estudada do Expressionismo literário, no qual discernia os elementos de blefe e insinceridade" (SCHOLEM, G. 2008, p. 137). Mesmo tendo contato com o Cabaré Neopatético (Neopatetisches Kabarett) - uma das células iniciais do Expressionismo, fundada em Berlim em 1910 - sua identificação com o movimento é limitada (Ibidem, p. 24).

Se diferenciando da afirmação do Expressionismo feita por Bloch e do Surrealismo feita posteriormente por Benjamin; Kracauer nunca colocou as vanguardas históricas enquanto paradigma de seus juízos estéticos. Mas reconhecia a legitimidade e a importância desses movimentos. Prova disto são suas simpatias em relação ao cinema experimental de Fernand Léger, Alberto Cavalcanti, René Clair, Hans Richter, entre outros, e sua admiração pelo cinema soviético, em especial Serguei Eisenstein (KRACAUER, S., 2009, p.25) e Dziga Vertov (KRACAUER, S., 1988, p.216).

Nos artigos escritos para o Frankfurter Zeitung a partir de 1927, Kracauer já apresenta sua perspectiva teórica que se distancia de sua posição ambivalente e se volta para uma crítica da ideologia, investigando as fórmulas ideológicas pelas quais o cinema converte contradições sociais e econômicas em fábulas de sucesso individual. Nesse sentido, seu texto Cinema 1928, (KRACAUER, S., 2009, pp. 327-342) analisa toda uma produção cujas qualidades técnicas tinham por finalidade o culto da evasão e da irrealidade, em que proletários (ou de camadas médias proletarizadas) tornam-se bem aventurados. Esse culto a evasão e a irrealidade se dá formalmente na tendência do cinema alemão de posicionar a câmera nos estúdios, percorrendo tempos e espaços distantes que são completamente irrelevantes para o momento. A realidade social é volatizada, petrificada e desfigurada, onde a superfície da tela é preenchida com imagens que falsificam a imagem do existente.

Posteriormente, já em seu exílio parisiense, Kracauer redige uma série de artigos para a Neue Züricher Zeitung, dentre os quais se destaca "O cinema expressionista" [Der expressionistische Film], publicado em 1939. Nele, Kracauer analisa os filmes com inequívoca estética expressionista (marcantes no período até 1924), mas dentro de um enfoque voltado para a perspectiva do culto da evasão, que caracteriza seus ensaios a partir de 1927. Para Kracauer, diretores como Fritz Lang, Murnau e Paul Leni, entre outros, dirigiram filmes seguindo a mesma orientação: "O que há de comum entre eles é que são encenados numa esfera inteiramente irreal e não deixam de lado qualquer possibilidade de produzir o horror" (KRACAUER apud MACHADO, C.E.J., 2007, p. 196). Do mesmo modo, a predileção pelas lendas antigas e pelas figuras de fantasmas, vampiros, assassinos e loucos. Representações que expressam o medo e o horror.

O mundo exterior, marcado pela miséria e inflação hiperbólica resultante das humilhantes condições do tratado de Versalhes, é um pesadelo coletivo que toma conta da população, e esta, ao invés de uma confrontação sóbria com a realidade social, se entrega a evasão como alternativa. Para Kracauer, a irrealidade dos filmes não é decorrente do uso da decoração expressionista, inspirada no teatro, mas é "conscientemente irreal" (Ibidem, 2007, p. 197) Nesse sentido, a estética teatral expressionista foi assimilada pela então emergente indústria cultural enquanto configuração desse culto da evasão e da irrealidade. Assim sendo, não só envolve a decoração cênica, mas o próprio trabalho estilizado dos atores, que 
concentravam sua tensão nos gestos que ultrapassavam a realidade visível para expressar a alma exaltada, que levou a esse voltar para dentro de si como válvula de escape ante o caos e o desespero da realidade.

Como emblema desta questão, podemos observar que no período áureo do Expressionismo no cinema, que vai de Caligari até 1924, é abordado por Kracauer nos capítulos 5 e 6 de seu livro De Caligari a Hitler, intitulados, respectivamente, "Caligari” e "Procissão de déspotas" (KRACAUER, S., 1988, pp. 78-107). Neles, Kracauer se detêm sobre dois tipos básicos presentes nos filmes do período: o tirano e autômato.

Embora a personificação do tirano já estivesse presente em Homunculos (1916), de Otto Rippert e a do autômato na primeira versão de O Golem (1915), de Paul Wegener e Henrik Galeen, foi em O Gabinete do Dr. Caligari (1919) de Robert Wiene, que adquiriram sua forma mais bem acabada e estilizada à maneira expressionistas, nas caracterizações fantasmagóricas de Werner Krauss (Caligari) e Conrad Veidt (Cesare). Nesse filme, o jogo dos atores integra-se à decoração, aos cenários, aos figurinos e às maquiagens, como se gravuras expressionistas adquirissem vida e se movessem. Krauss e Veidt levam para as telas todas as características da atuação expressionista: o arfar, a deformidade, a tensão concentrada nas mãos e na face, onde gestos bruscos sem transição ou nuances intermediárias às vezes não se completam. Se (de acordo com o roteiro original de Hans Janowicz e Carl Mayer) Caligari em seu uniforme de professor é o protótipo da autoridade que não vê limites em sua sede de poder e autoridade, o sonâmbulo Cesare com sua malha preta representa o assassino sem vontade própria usado como mero instrumento da vontade de potência de Caligari. Porém, ao se adotar a história moldura - em que toda a narrativa e configuração não passa de alucinação de um louco - todo o potencial radical de crítica a toda forma de autoridade que advinha da proposta de Janowicz e Mayer de acordo com a experiência da Primeira Guerra se enfraquece. Pelo contrário, se torna uma representação da submissão, ao se saber que Caligari não passa de paranóia de um louco e que se trata do diretor do hospício, apresentado como uma figura tranquila e benevolente. Assim, a própria estética expressionista - que a princípio, seria utilizada em seu potencial revolucionário - é anestesiada em sua radicalidade ao ser conciliada como entretenimento altamente artístico dentro da indústria cultural, no caso, sendo produção da UFA.

Toda essa transformação do significado latente de $O$ Gabinete do Dr. Caligari tem, segundo Kracauer, ligações profundas com os próprios acontecimentos ocorridos no ano de sua produção. 1919 foi um ano marcado pelo fracasso definitivo de uma revolução que parecia eminente. Os socialdemocratas se mostraram incapazes de remover as forças mais conservadoras da sociedade alemã ao mesmo tempo em que os setores revolucionários operários liderados por Rosa Luxemburgo e Karl Liebknecht - assassinados por setores paramilitares de direita denominados com total cumplicidade da socialdemocracia alemã eram massacrados. Esses grupos paramilitares de direita, denominados Freikorps, tinham suas raízes nos Junkers (a aristocracia militar nos tempos de Bismarck) e posteriormente, seus membros (marcados por setores militares ressentidos com a derrota na Guerra, do lumpenproletariado e dos chamados estratos médios) serão decisivos para a formação das policias hitleristas.

Concluindo, nesse pequeno texto fizemos um trajeto da reavaliação da alegoria barroca pelo Expressionismo feito por Benjamin, assinalando suas proximidades com 
Kracauer, no que tange ao vazio e mal-estar diante da modernidade a atenção dada aos vestígios e ás manifestações culturais desprezadas por uma elite intelectual compenetrada em valores ultrapassados, assim como apontamentos ao que diz respeito ao posicionamentos de ambos em relação a estética expressionista e ao uso da alegoria do autômato por Benjamin e pelo cinema expressionista na República de Weimar. Consideramos que o extenso legado do Expressionismo, principalmente no cinema (Filmes de horror da Universal dos anos 30, Filmnoir, Marcel Carné, Orson Welles, Bergman, Fassbinder, Blade-Runner, etc.), constata o quanto sua estética se enquadra a campos formais e estilísticos tão diferentes, que comprovam todo o seu potencial alegórico se prestando a uma pluralidade de leituras e significações. Nesse sentido, o trajeto de Kracauer - se assemelhando da linha irracionalista da filosofia alemã, traçada por Lukács em A Destruição da Razão, que levaria ao nazismo - é apenas uma interpretação entre várias possíveis. O Expressionismo talvez seja o mais explosivo e ambivalente dos movimentos das vanguardas históricas e que já trazia, em sua defesa da subjetividade, o imperativo para diferentes estilos e concepções entre os vários artistas ligados ao movimento e a estética. No campo político, provocava a desconfiança dos comunistas e, ao mesmo tempo, magnetizava artistas da esquerda; cativou artistas considerados conservadores em sua fase inicial (observemos o caso do pintor Emil Nolde e do poeta Gottfried Benn), para na década de 30 ser desprezado pelo nazismo como arte degenerada [Entartete Kunst] (que incluía as obras de Nolde) e bolchevismo cultural. Na verdade, a concepção de arte nazista estava muito mais próxima do classicismo, mesmo que corrompido em um neoclássico medíocre. Acrescenta-se também o fato de estar incluído nas fileiras expressionistas inúmeros artistas de ascendência judaica. Portanto, o Expressionismo nos parece uma das mais perfeitas configurações do que denominamos polissemia em arte e que é parte de sua particularidade alegórica.

\section{REFERENCIAS BIBLIOGRÁFICAS:}

BENJAMIN, Walter. A obra de arte na época de sua reprodutibilidade técnica. (2 $2^{\mathrm{a}}$ versão). Tradução, apresentação e notas: Francisco de Ambrosis Pinheiro Machado. Porto Alegre: Editora Zouk, 2012.

. A origem do drama trágico alemão. Edição e tradução de João Barrento. Belo Horizonte: Autêntica Editora, 2011.

Obras escolhidas: magia, técnica, arte e política. Tradução: Sergio Paulo Rouanet. São Paulo; Brasiliense, 1994. v. 1.

BRETAS, Aléxia. A constelação do sonho em Walter Benjamin. São Paulo: Humanitas, 2008.

BÜRGER, Peter. Teoria da vanguarda. Tradução: José Pedro Antunes. $1^{\text {a }}$ edição Cosac Naify Portátil. São Paulo: Cosac Naify, 2012.

EISNER, Lotte H. A tela demoníaca: as influências de Max Reinhardt e do expressionismo. Tradução: Lucia Nagib. São Paulo: Paz e Terra, 2002.

GAGNEBIN, Jeanne-Marie. História e Narração em Walter Benjamin. São Paulo:

Perspectiva, 2011. (Estudos: 142 / dirigida por J. Guinsburg) 
KRACAUER, Siegfried. O ornamento da massa. Tradução: Carlos Eduardo Jordão Machado e Marlene Holzhausen. São Paulo: Cosac Naify, 2009.

De Caligari a Hitler: uma história psicológica do cinema alemão. Tradução: Tereza Ottoni. Rio de Janeiro: Zahar, 1988.

LÖWY, Michael. Romantismo e messianismo: ensaios sobre Lukács e Benjamin. Tradução: Myriam Vera Baptista e Magdalena Pizante. São Paulo: Editora Perspectiva, 2008

. Walter Benjamin: aviso de incêndio; uma leitura das teses "Sobre o conceito de história”. Tradução de Wanda Nogueira Caldeira Brant, [tradução das teses] Jeanne Marie Gagnebin, Marcos Lutz Müller. São Paulo: Boitempo, 2005.

LUKÁCS, Georg. Teoria do Romance. Tradução: José Marcos Mariani de Macedo. São Paulo: Editora 34, 2009

MACHADO, Carlos Eduardo Jordão. A exterritorialidade como condição do apátrida transcendental: sobre Siegfried Kracauer e Georg Lukács. Significação, São Paulo, n. 27, p.181-207, 2007.

Um capítulo sobre a Modernidade Estética: Debate Sobre o Expressionismo. São Paulo: Ed. da Unesp, 1998.

NAZÁRIO, Luiz. As sombras móveis: atualidade do cinema mudo. Belo Horizonte: Ed. da UFMG, 1999.

SCHOLEM, Gershom. Walter Benjamin: a história de uma amizade. Tradução de Geraldo Gerson de Souza e Shizuka Kuchiki. São Paulo: Perspectiva, 1989. 